\title{
Long-term effects of tramadol on the reproductive function of male albino rats: an experimental biochemical and histopathological study
}

\author{
Sherein Salah', Mohamed Wagih² ${ }^{*}$, Amr Zaki ${ }^{3}$, Wael Fathy ${ }^{4}$ and Amir Eid ${ }^{3}$
}

\begin{abstract}
Background: Tramadol is a commonly abused erotic drug that recently has gained popularity among young men. It is a centrally acting analgesic used to treat moderate to severe pain. This study aimed to evaluate the chronic toxic effects of tramadol on the reproductive system of male albino rats. It was carried out on 60 rats weighing 130-150 g divided into two groups. The first group (control group) included 30 rats and received normal saline $0.9 \% 1 \mathrm{ml} /$ day orally for 45 days. The second group (tramadol group) included 30 rats and received tramadol 60 $\mathrm{mg} / \mathrm{kg}$ subcutaneously three times per week for 45 days. Blood samples were obtained from the animals and analysed for serum testosterone, FSH, LH and prolactin levels. Also, the testes were excised and examined for histopathological changes.

Results: The results revealed that there was a decrease in the serum levels of testosterone $(P=0.009), F S H(P=0.057)$ and LH $(P=0.002)$ and an increase in the serum prolactin level $(P=0.166)$ in animals treated with tramadol. In addition, histopathological examination revealed distinct abnormal changes compared with the corresponding control group.

Conclusion: The present study affirms the deleterious chronic toxic effects of tramadol on the reproductive system of male albino rats. It is thus advisable that tramadol should be used with caution with appropriate dose monitoring to avoid its undesirable side effects on male fertility.
\end{abstract}

Keywords: Tramadol, Chronic, Toxicity, Reproduction

\section{Background}

Recently, the use of sexual stimulants like opioids has gained a wide popularity among young men without erectile dysfunction [1]. Reasons for the use of sexual stimulants in the absence of erectile disease include the urge to augment sexual drives, the desire to achieve a harder and long-lasting erection, the urge for higher coital frequency and the willingness to delay ejaculation [2]. Previous studies had reported that erotic medications used in the treatment of erectile dysfunction and premature ejaculation are

\footnotetext{
* Correspondence: mohamwagih@hotmail.com;

mohamed.wagih@med.bsu.edu.eg

${ }^{2}$ Department of Pathology, Faculty of Medicine, Beni-Suef University, Beni

Suef, Egypt

Full list of author information is available at the end of the article
}

widely abused and are associated with various degrees of discernible side effects [3].

Tramadol is a centrally acting analgesic with a dual mode of action, including an opioid and non-opioid component. It is an agonist of the opioid receptors, but in addition, it also inhibits the serotonin and norepinephrine reuptake enhancing the inhibitory effects on pain transmission in the spinal cord [4]. It is prescribed to treat pain of moderate to severe intensity [5]. The reported side effects of tramadol include headache, dizziness, somnolence, nausea, constipation, sweating, pruritus and central nervous system stimulation [6].

Tramadol has low plasma protein binding (20\%) and wide tissue distribution. It is eliminated primarily through the liver (metabolism to O-desmethyl tramadol and $\mathrm{N}$-desmethyl tramadol) and partially through the 
kidney (up to $30 \%$ of dose). O-desmethyl tramadol has a considerably greater affinity for opioid receptors than the parent drug and is a more powerful analgesic. The half-lives of the active ingredients range from 4.5 to 9.5 $\mathrm{h}$, and total plasma elimination of tramadol is reasonably high $(600 \mathrm{ml} / \mathrm{min})$. The interaction potential of tramadol is considered negligible because it does not influence the disposition of other drugs [7]. Although tramadol has apparently a low potential for abuse, yet there is reported evidence of abuse, addiction and withdrawal [8]. Repeated tramadol administration may lead to accumulation of toxic metabolites, increase the risk of pharmacokinetic interactions and/or decrease its elimination, thus increasing its potential for toxicity [9]. Chronic use of tramadol has been reported to adversely affect the male reproductive tissues. For example, Safarinejad et al. [10] demonstrated serious reproductive toxicity, like increased sperm DNA damage mediated by testicular oxidative damage.

The objectives of the present work are to evaluate the biochemical and testicular histopathological changes induced by chronic administration of tramadol in male albino rats. No doubt that rodents have long served as good research subjects due to their biological similarity with humans, short life-cycles so they can be easily studied throughout their whole life-span and ease of control of surrounding conditions (e.g. diet, temperature, lighting), which would be difficult to do with people.

\section{Methods}

This experimental work is a toxicological study of a commonly used erotic drug on the reproductive system of male albino rats. It was carried out in accordance with the national and institutional ethics for the care and use of laboratory animals. The study included biochemical analysis of the serum levels of testosterone, prolactin, FSH and $\mathrm{LH}$ in the rats after subcutaneous injection of tramadol, in addition to histopathological examination of the excised testes.

\section{Drugs}

Tramal (tramadol $\mathrm{HCl}$ ), 100-mg ampoules, were purchased from Minapharm Pharmaceutical Company, Cairo, Egypt.

\section{Laboratory animals}

The animals were obtained and maintained in the animal house facility of Beni-Suef University, Egypt. They were kept in metabolic cages at $22 \pm 2{ }^{\circ} \mathrm{C}$ with a humidity of $50 \pm 5 \%$ and a 12 -h/12-h light/dark cycles. They had free access to water and rat chow ad libitum. The acclimatization of the animals lasted for 7 days before tramadol administration.

\section{Study design}

The animals (male albino rats, weighing 130-150 g, 8-10 weeks old) were randomly allocated into two groups. Sample size was determined after wide review of literature and available methods, e.g. E and Power analysis methods. The first group (control group) included 30 normal male rats, each received normal saline $0.9 \% 1 \mathrm{ml} /$ day orally by gavage for 45 days. The second group (tramadol group) included 30 male rats and received tramadol $60 \mathrm{mg} / \mathrm{kg}$ subcutaneously three times per week for 45 days. Administered doses and routes of administration were based on a wide literature search as well as preliminary studies.

\section{Sampling}

The rats were sacrificed under anaesthesia with sodium thiopental (a well-known general anaethestic commonly used in rats), and blood samples were obtained from each animal and immediately poured into heparinized tubes. The sera were centrifuged and preserved at $-20^{\circ} \mathrm{C}$ until used for biochemical analysis. The testes were excised, cleared of the adherent connective tissue, fixed in Bouin solution and processed for histopathological examination.

\section{Biochemical analysis}

The serum levels of testosterone, FSH, LH and prolactin were determined using ELISA kits according to the manufacturer's instructions.

\section{Histopathological study}

After fixation, the specimens were dehydrated in alcohol, cleared in xylene and embedded in paraffin. Paraffin sections of $5-\mu \mathrm{m}$ thickness were cut by a rotatory microtome, mounted on clean slides and stained with haematoxylin and eosin for histopathological examination.

\section{Statistical analysis}

The collected data were expressed as means \pm standard deviation for all parameters. For comparison of the statistical significance between the studied groups, Student's $t$ test was used. A $P$ value less that 0.05 was set to represent statistical significance.

\section{Results}

\section{Biochemical findings}

The results revealed that administration of tramadol 60 $\mathrm{mg} / \mathrm{kg}$ three times per week for 45 days statistically reduced the serum testosterone level accompanied by an increase in the serum prolactin level and a decrease in the serum LH levels compared to the control group (Table 1). Concerning FSH, a decrease in the serum level was observed in the tramadol group but with a borderline significance $(P=0.057)$. 
Table 1 Mean serum levels of FSH, LH, testosterone and prolactin in the control and tramadol groups

\begin{tabular}{llll}
\hline & $\begin{array}{l}\text { Control } \\
\text { group }\end{array}$ & $\begin{array}{l}\text { Tramadol } \\
\text { group }\end{array}$ & $P$ value \\
\hline FSH $(\mathrm{mlU} / \mathrm{ml})$ & $0.106 \pm 0.009$ & $0.063 \pm 0.004$ & 0.057 \\
$\mathrm{LH}(\mathrm{mlU} / \mathrm{ml})$ & $0.52 \pm 0.006$ & $0.088 \pm 0.015$ & $0.002^{*}$ \\
Testosterone $(\mathrm{ng} / \mathrm{ml})$ & $5.34 \pm 0.084$ & $2.274 \pm 0.139$ & $0.009^{*}$ \\
Prolactin $(\mathrm{ng} / \mathrm{ml})$ & $1.06 \pm 0.084$ & $4.42 \pm 0.329$ & 0.166 \\
\hline
\end{tabular}

\section{Histopathological findings}

The testicular sections prepared from the control group showed normal appearance of the seminiferous tubules and interstitial tissue. The tubules were lined with germinal cells and supporting sertoli cells. The germinal cells were arranged in several layers from the basement membrane towards the lumen of the tubules. These layers are formed of a series of spermatogenic cells at different stages of maturation including spermatogonia, primary spermatocytes, secondary spermatocytes, spermatids and mature sperms. The interstitial tissue stroma between the seminiferous tubules contained the interstitial cells of Leydig (Fig. 1).

Sections prepared from the animals treated with tramadol revealed distinct histological changes with abnormal appearance of the germinal epithelium. The majority of the seminiferous tubules exhibited damage with disorganized spermatogenic cells that showed prominent multiple desquamations and vacuolar degeneration. Numerous apoptotic and multinucleated giant cells were also seen. Many spermatogenic cells appeared with pyknotic nuclei. Furthermore, absence of spermatozoa was clearly recognized. The interstitial tissue showed marked edema and vascular congestion. In addition, foci of dystrophic

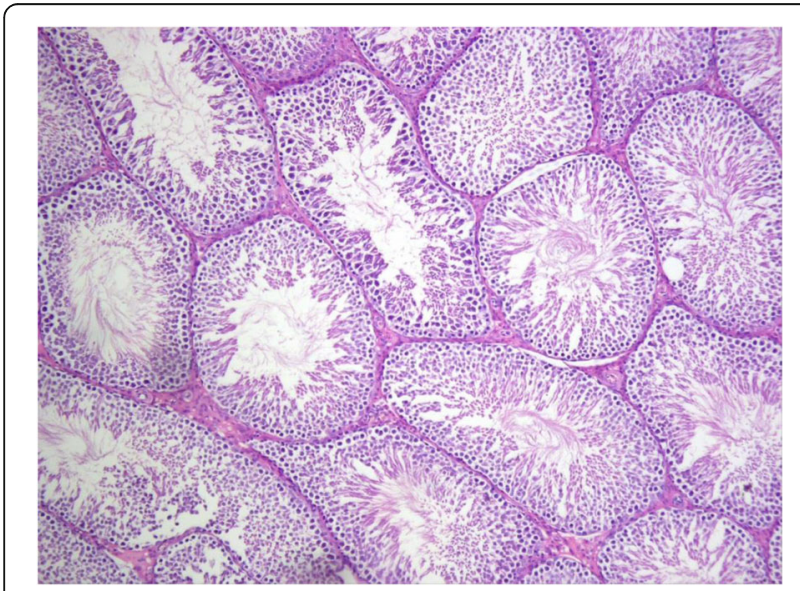

Fig. 1 Testicular section from the control group showing normal seminiferous tubules with normal spermatogenesis $(H \& E, \times 100)$ calcification were found in some cases. Leydig cells were markedly reduced (Figs. 2, 3, 4, 5 and 6).

\section{Discussion}

Sex-enhancing drugs have become some of the most prescribed and abused pharmaceuticals in the last years. Indeed, it is reasonable to believe that recreational use of erotic medications may exceed their recommended medical use [3].

Several studies on the effect of chronic consumption of opioids on the male reproductive system have revolved around testicular oxidative stress as the mediator of reproductive toxicity. Opioids are among the most useful therapeutic drugs for pain management. Their side effects have been a wide subject of research. However, one of their side effects, namely male hypogonadism, has not been fully elucidated.

The current study revealed that rats treated with tramadol had lower serum levels of testosterone $(P=0.009)$, FSH (with a borderline significance) $(P=0.057)$ and $\mathrm{LH}$ $(P=0.002)$ and an increased prolactin level $(P=0.166)$ compared with the control rats. The reduced serum levels of FSH and LH were explained by Bliesener et al. [11] who showed that the opioid effect on the gonadotropinreleasing hormone $(\mathrm{GnRH})$ is mediated partly through the increased prolactin levels. In addition, Pimpinellei et al. [12] reported that increased prolactin synthesis could directly inhibit testosterone synthesis. Moreover, ElGaafarawy [13] reported the reduction of serum levels of $\mathrm{FSH}, \mathrm{LH}$ and testosterone and the induction of prolactin secretion following paroxetine (opioid with tramadol-like action acting on opioid receptors) treatment. The results suggest that tramadol administration might influence the release of testosterone via the hypothalamo-hypophyseal-

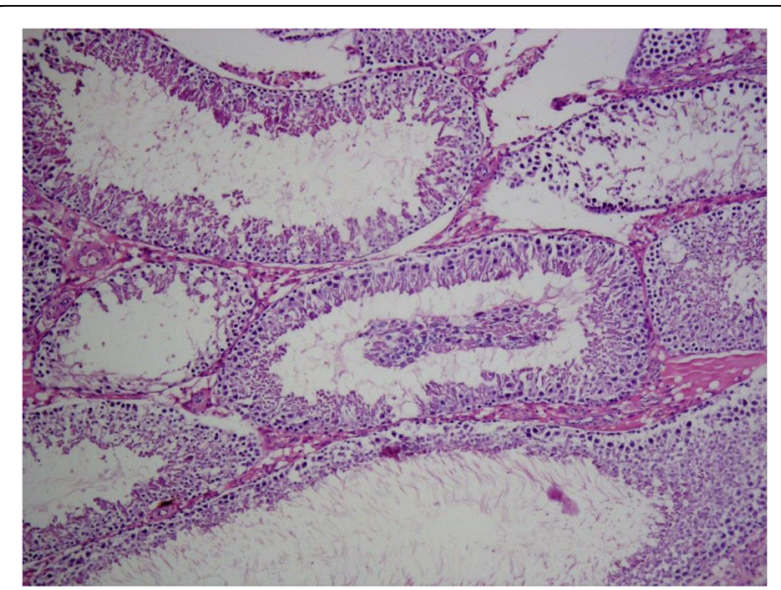

Fig. 2 Testicular section from the tramadol group showing disorganized spermatogenesis with focal exfoliation of desquamated germinal cells in the lumen of seminiferous tubules $(H \& E, \times 100)$ 


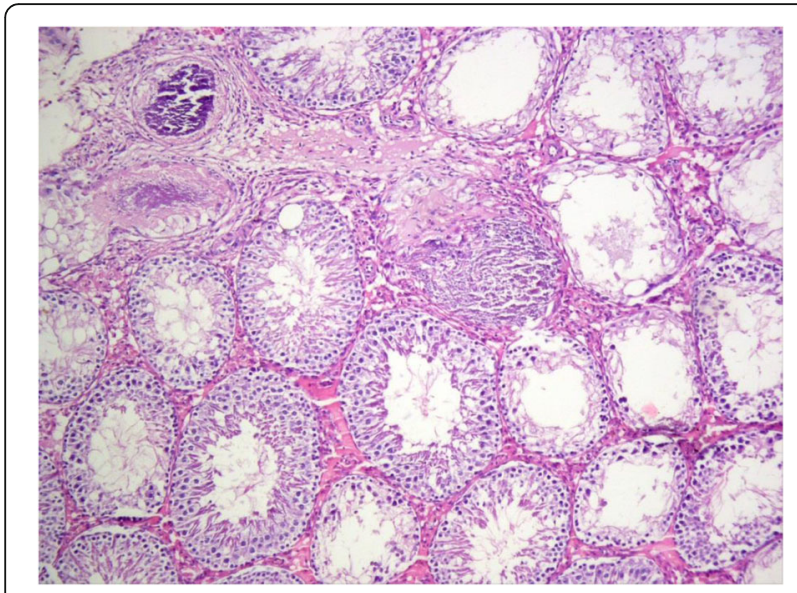

Fig. 3 Testicular section from the tramadol group showing vacuolar degeneration with absent spermatogenesis in some seminiferous tubules. Focal calcification was also regarded $(H \& E, \times 100)$ gonadal axis. In addition, it is well known that $\mathrm{LH}$ is regulated by numerous neurotransmitters, including endogenous opioid peptides [14]. The present results were also explained by Katz [15]. The long-term effects of opioids on the endocrine system include reducing testosterone levels by central reduction of LH release. There are peripheral effects on the testis as well since tramadol also increases aromatization of testosterone to estradiol [16]. It is noteworthy that in our study the reduction in FSH was with a borderline significance $(P=0.057)$. This reduction may not be sufficient enough to reach a marked statistical significance but it may be of biological significance. Negative feedback effect may also play a role in this effect as indicated by Farag et al. [17].

Opioids are well known to affect sexual drive in male humans and rodents [18]. Mckim [19] reported that

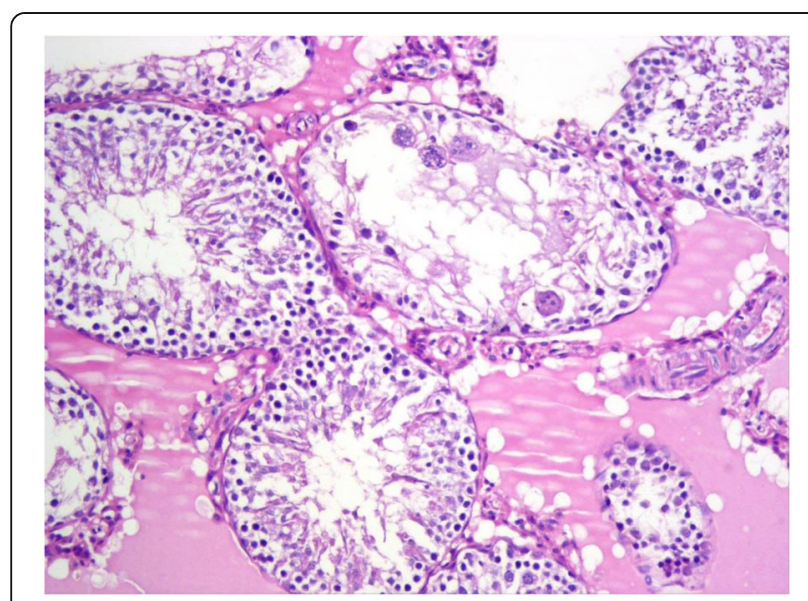

Fig. 4 Testicular section from the tramadol group showing focal vacuolar degeneration with prominent intratubular giant cells and interstitial oedema $(H \& E, \times 200)$

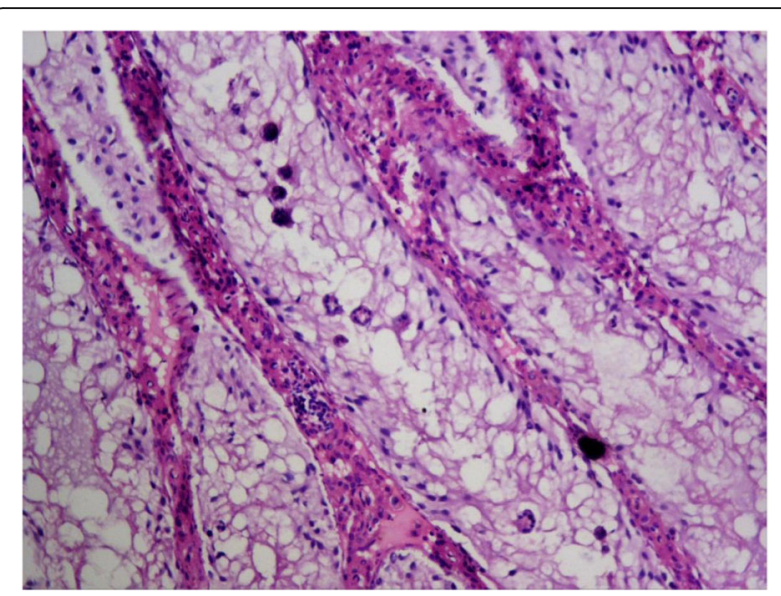

Fig. 5 Testicular section from the tramadol group showing vacuolar degeneration with intratubular apoptotic bodies and abnormal giant cells $(H \& E, \times 200)$

opioids decrease the levels of sex hormones and result in diminished fertility of both males and females. Azari et al. [20] detected a significant association between chronic tramadol administration and impaired quality of sperm parameters including a reduction in sperm count, motility and vitality in mice. Also, in a study conducted by Heidari et al. [21], chronic administration of methadone had deleterious effects on the testicular tissue in male rats. Furthermore, Babaei et al. [22] showed that long-term administration of buprenorphine could reduce the serum testosterone level, damage spermatogenesis and affect fertility in male rats.

Although the cellular effects of long-term administration of tramadol are not fully understood [23], much of their toxic effects may be attributed to lipid peroxidation [24]. The spermatozoa are highly susceptible to peroxidative

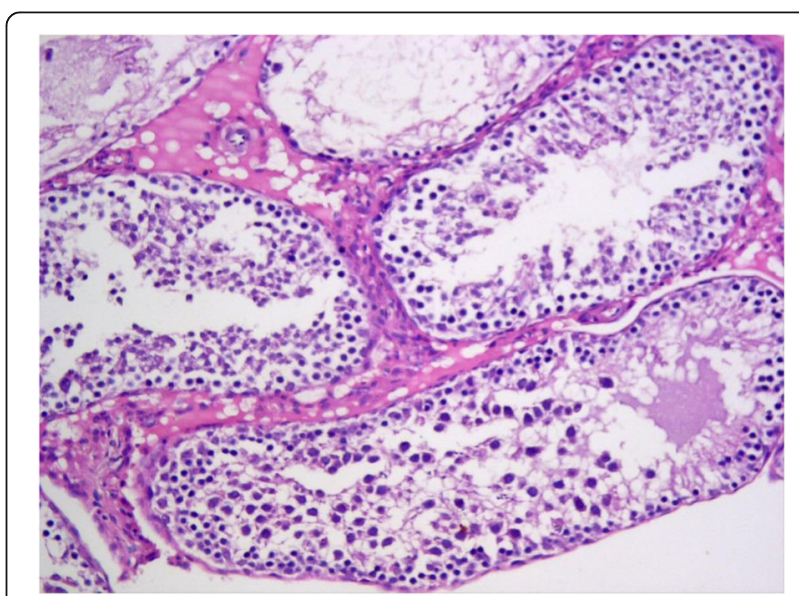

Fig. 6 Testicular section from the tramadol group showing disorganized spermatogenesis, vacuolar degeneration, interstitial oedema and reduced number of Leydig cells $(H \& E, \times 200)$ 
damage due to the high content of polyunsaturated fatty acids present within their plasma membranes [25]. The increased lipid peroxidation and altered membrane can induce sperm dysfunction through impaired metabolism, motility and oxidative damage to sperm DNA [26]. Superoxide dismutase (SOD) was found to protect human spermatozoa from the oxidative damage [27]. Safarinejad et al. [10] demonstrated a significant reduction in SOD activity in the semen of opioid abusers. El-Gaafarawi [13] reported a significant increase in serum malondialdehyde levels in tramadol-treated rats indicating an increase in lipid peroxidation. A significant decrease in sperm quality and an increase in spermatozoa DNA fragmentation in the semen of opioid abusers were reported by Safarinejad et al. [10]. Furthermore, long-term exposure to heroin (opioid with tramadol-like action acting on opioid receptors) causes a decrease in sperm motility because it has been linked to oxidative stress [28]. Also, an increase in sperm DNA damage was observed following amphetamine administration in male rats [29].

The pathological features in the current study are indicative of tramadol toxic effect on the male reproductive organs. The data obtained from histopathological examination showed that long-term administration of tramadol caused frank testicular atrophic changes. A similar finding together with induced structural sperm abnormalities have been observed by Azari et al. [20]. They added that such effects may be attributed to the spermicidal effect of tramadol. Reuhl et al. [30] showed thickening of the basement membrane of seminiferous tubules, tubular atrophy and arrest of cell maturation in opioid abusers. It is well known that changes in the basement membrane thickness can impair testicular metabolism promoting tubular atrophy. The duration of drug abuse affects to a great extent the degree of testicular damage [31]. The effect of long-term administration of tramadol on the testicular function was investigated by Ahmed and Kurkar [32]. In their study, the studied rats received $40 \mathrm{mg} / \mathrm{kg}$ of tramadol as subcutaneous injection three times per week for 8 weeks. Their results revealed that endothelial nitric oxide synthase expression was upregulated in the testicular tissues. Also, tramadol reduced the sperm count, motility and the number of Leydig cells. They concluded that chronic administration of tramadol affects the testicular function of adult male rats through overproduction of nitric oxide and the induction of oxidative stress. The long-term effects of tramadol on the testicular tissue and spermatogenesis have also been evaluated in previous experimental studies on rats. Ghoneim et al. [33] reported that chronic usage of tramadol induced arrest of spermatogenesis together with sloughing of the germinal epithelium, thickening of the basement membrane of the seminiferous tubules and apoptotic changes. Further, in another study, Abou El Fatoh et al. [34] reported the presence of severe diffuse testicular degeneration without spermatogenesis following long-term administration of tramadol. The spermatocytes were mostly necrotic.

Animals have been used to study the kinetic and dynamic aspects of toxicants, and they offer the opportunity of providing evidence on the translational value of animal models for humans. However, they have to be cautiously interpreted when applying them to the humans. No doubt that epidemiological studies are still the best method for evaluating the human risk and the influences of environmental toxicants $[35,36]$. In the current research, however, it would be somehow problematic to find normal subjects chronically administering pain relievers such as drug abusers. Therefore, more animal studies may be useful in this respect.

\section{Conclusions}

In conclusion, the data obtained from this study show that long-term administration of tramadol has adverse effects on adult male rats on the biochemical and histopathological levels. It is thus advisable that tramadol abuse should be avoided without medical description and users of tramadol should seek medical help to minimize its undesirable effects. However, further studies on the effect of tramadol on sex hormone levels and changes in the quality of sperm parameters are recommended.

\section{Acknowledgements \\ The authors would like to thank Zahy Elsayed for his excellent technical contribution to this work.}

\section{Authors' contributions}

SS contributed in the design and supervision of the practical part. MW contributed in the design, histopathological examination, analysis of results and drafting the manuscript. AZ shared in the study design and data interpretation. WF has a major contribution in the practical part, analysis and discussion of results. AE contributed mainly in the data collection, practical part, revising and drafting the manuscript. All authors read and approved the final manuscript.

\section{Funding}

This work was conducted through collaboration between different research facilities in Egypt. No specific financial support was received by the authors during this study.

\section{Availability of data and materials}

Data will not be shared because they are completely included within the manuscript.

\section{Ethics approval}

The experimental procedures were conducted in accordance with the $\mathrm{NIH}$ guidelines for the care and use of laboratory animals.

\section{Consent for publication}

Not applicable.

\section{Competing interests}

The authors declare that they have no competing interests.

\section{Author details}

${ }^{1}$ Department of Forensic Medicine and Clinical Toxicology, Faculty of Medicine, Cairo University, Cairo, Egypt. ${ }^{2}$ Department of Pathology, Faculty of Medicine, Beni-Suef University, Beni Suef, Egypt. ${ }^{3}$ Department of Forensic 
Medicine and Clinical Toxicology, Faculty of Medicine, Beni-Suef University, Beni Suef, Egypt. ${ }^{4}$ Department of Toxic Compounds and Addict Drugs, Forensic Medicine Authority, Ministry of Justice, Cairo, Egypt.

Received: 17 July 2019 Accepted: 2 August 2019

Published online: 05 September 2019

\section{References}

1. Nna V, Akpan U, Osim E (2016) Hyperprolactinemia contributes to reproductive deficit in male rats chronically administered PDE5 inhibitors (sildenafil and tadalafil) and opioid (tramadol). Asian Pac J Reprod 5:381-386

2. Bechara A, Casabe A, Bonis W, Helen A, Bertolino M (2010) Recreational use of phosphodiesterase type 5 inhibitors by healthy young men. J Sex Med 7: 3736-3742

3. Nna VU, Ani EJ, Ofutet EO, Ofem OE, Iroh CE, Osim EE (2014) Recurrent side effects following chronic recreational use of sexual stimulants among male subjects in Calabar, Cross River State, Nigeria. Der Pharmacia Lettre 6:56-61

4. Oliva P, Aurilio C, Massimo F (2002) The antinociceptive effect of tramadol in the formalin test is mediated by the serotonergic component. Eur J Pharmacol. 445:179-185

5. Lamont L, Mathews K (2007) Opioids, non-steroidal anti-inflammatories and analgesic adjuvants. In: Lumb and Jones, Veterinary anesthesia, 4th edn. Blackwell publishing, Towa, p 264

6. Kabel L, Von Puijenbroek E (2005) Side effects of tramadol. 12 years of experience in the Netherlands. Ned Tijdschr Greneeskd 149:754-757

7. Klotz U (2003) Tramadol - the impact of its pharmacokinetic and pharmacodynamic properties on the clinical management of pain. Arzneimittelforschung 53(53):681-687

8. McDiarmid T, Mackler I (2005) What is the addiction risk associated with tramadol? J Fam Practice 54CD:72-74

9. Shadina S, Soltaninejad K, Heydari K, Sasanian G, Abdollahi M (2013) Tramado intoxication: a review of all 114 cases. Hum Exp Toxicol 27:201-205

10. Safarinejad MR, Asgari SA, Farshi AR, Ghaedi G, Kolahi AA, Iravani S, Khoshdel AR (2013) The effects of opiate consumption on serum reproductive hormone levels, sperm parameters, seminal plasma antioxidant capacity and sperm DNA integrity. Reprod Toxicol 36:18-23

11. Bliesener N, Albrecht S, Schwager A, Weckbecker K, Lichtermann D, Klingmller D (2005) Plasma testosterone and sexual function in men receiving buprenorphine maintenance for opioid dependence. J Clin Endocrinol Metab 901:203-206

12. Pimpinelli F, Parenti M, Guzzi F, Piva F, Hokfelt T, Maggi R (2006) Presence of delta opioid receptors on a subset of hypothalamic gonadotropin releasing hormone $(\mathrm{GnRH})$ neurons. Brain Res 1070:15-23

13. El-Gaafarawi I (2006) Biochemical toxicity induced by tramadol administration in male rats. The Egyptian Journal of Hospital Medicine 23:353-362

14. Gore AC (2001) Gonadotropin releasing hormone neurons, NMDA receptors and their regulation by steroid hormones across the reproductive life cycle. Brain Res Rev 37:235-248

15. Katz N (2005) The impact of opioids on the endocrine system. Pain Manag. Round 19:1-6

16. Ceccarelli I, De-Padova AM, Fiorenzani P, Massafra C, Aloisi AM (2006) Single opioid administration modifies gonadal steroids in both the CNS and plasma of male rats. Neuroscience 140:929-937

17. Farag A, Basha M, Amin S, Elnaidany N, Elhelbawy N, Mostafa M, Khodier S, Ibrahem R, Mahfouz R (2018) Tramadol (opioid) abuse is associated with a dose- and time-dependent poor sperm quality and hyperprolactinaemia in young men. Andrologia 21:e13026

18. Cicero T, Davisb L, Larigenac M, Meyera E, Schlegela M (2002) Chronic opiate exposure in the male rat adversely affects fertility. Pharmacol Biochem Behav 72:157-163

19. Mckim W (2003) Drugs and behavior: an introduction to behavioral pharmacology, $5^{\text {th }}$ ed. Prentis Hall, New Jersey, p 243

20. Azari O, Emadi L, Kheirandishet R, Bafti H, Reza M, Nejad E, Faroghi F (2014) The effect of long term administration of tramadol on epididymal sperm quality and testicular tissue in mice. Iran J Vet Surg 9:23-30

21. Heidari Z, Mahmoudzadeh-Sagheb H, Kohan F (2012) A quantitative and qualitative study of rat testis following administration of methadone and buprenorphine. Int High Risk Behav Addict 1:14-17

22. Babaei H, Sepehri G, Kheirandish R, Abshenas J, Monshi M (2012) The effects of long term administration of buprenorphine on blood testosterone level and morphometrical and histopathological changes of mouse testis. Comp Clin Pathol 21:1527-1532

23. Atici S, Cinel I, Cinel L, Doruk N, Eskanderi G, Orual U (2005) Liver and kidney toxicity in chronic use of opioids: an experimental long term treatment model. J Biosci 30:245-252

24. Lurie E, Soloviova A, Alyabieva T, Kaplur A, Panchenko L, Shvets V (1995) Effect of novel aromatic derivative of GABA on lipid peroxidation in chronically morphinized rat. Biochem Biol Int 36:13-19

25. Aitken R, Backer H, Irvine (1995) The importance of sperm morphology in the assessment of male fertility. Hum Reprod 10:248-249

26. Cummins J, Jequier A, Kan R (1994) Molecular biology of human male infertility links with aging, mitochondrial genetics and oxidative stress. Mol Reprod Dev 37:345-362

27. Taylor C (2001) Antioxidant and reactive oxygen species in human fertility Environ Toxicol Pharmacol 10:189-198

28. Agirregoitia E, Valdiva A, Callacedo A, Casis L, Gil J, Subiran N (2006) Expression and localization of delta, kappa and mu-opioid receptors in human spermatozoa and implications for sperm motility. J Clin Endocrinol Metab 91:4969-4975

29. Barenys M, Macia N, Camps L, De Lapunte J, Gomez-Catalan J, Gorzalez-Linares J (2009) Chronic exposure to MDMA (ecstasy) increases DNA damage in sperm and alters testis histopathology in male rats. Toxicol Lett 191:40-46

30. Reuhl J, Bachl M, Schneider M, Lutz F, Bratzhe H (2001) Morphometric assessment of testicular changes in drug related fatalities. J Forensic Sci Int 115:171-181

31. Sorge R, Stewart J (2006) Effects of long term chronic buprenorphine treatment on the locomotor and nucleus acumens dopamine response to acute heroin and cocaine in rats. J Pharmacol Biochem Behav 84:300-305

32. Ahmed M, Kurkar A (2014) Effects of opioid (tramadol) treatment on testicular functions in adult male rats: the role of nitric oxide and oxidative stress. Clin Exp Pharmacol Physiol 41:317-323

33. Ghoneim F, Khalaf H, Elsamanoudy A Helaly A (2014) Effect of chronic usage of tramadol on motor cerebral cortex and testicular tissues of adult male albino rats and the effect of its withdrawal: histological, immunohistochemical and biochemical study. Int J Clin Exp Pathol 7:7323-7341

34. Abou El Fatoh M, Farag M, Sayed A, Kamel M, Abdel Hamid E (2014) Some biochemical, neurochemical, pharmacotoxicological and histopathological alterations induced by long term administration of tramadol in male rats. Int J Pharma Sci 4:565-571

35. Brent RL (2004) Utilization of animal studies to determine the effects and human risks of environmental toxicants (drugs, chemicals, and physical agents). Pediatrics 113:984-995

36. J v L, Leenaars M, Hooijmans C, Wever K, de Vries R, Ritskes-Hoitinga M (2013) Towards evidence-based translational research: the pros and cons of conducting systematic reviews of animal studies. ALTEX 30:256-257

\section{Publisher's Note}

Springer Nature remains neutral with regard to jurisdictional claims in published maps and institutional affiliations.

\section{Submit your manuscript to a SpringerOpen ${ }^{\bullet}$ journal and benefit from:}

- Convenient online submission

- Rigorous peer review

- Open access: articles freely available online

- High visibility within the field

Retaining the copyright to your article

Submit your next manuscript at $>$ springeropen.com 